Original Research Paper

\title{
Analisis Potensi Alam Desa Kwang Rundun Untuk Menunjang Konsep Ekowisata Serta Identifikasi Desa Kwang Rundun Sebagai Desa Wisata
}

\author{
Raissa Putri Nabella ${ }^{1}$, Dodit Adiyatma ${ }^{1}$, Nisrina Muniro $^{2}$, Nabilah ${ }^{2}$, Baiq Tania Febrianti $^{3}$, Rizki \\ Jagadraya $^{4}$, Lalu Japa ${ }^{5^{*}}$ \\ ${ }^{1}$ Pendidikan Bahasa Inggris, FKIP Universitas Mataram, Mataram; \\ ${ }^{2}$ Pendidikan Matematika, FKIP Universitas Mataram, Mataram; \\ ${ }^{3}$ PendidikanPancasila dan Kewarganegaraan, FKIP Universitas Mataram, Mataram; \\ ${ }^{4}$ Pendidikan Fisika, FKIP Universitas Mataram, Mataram; \\ ${ }^{5}$ Pendidikan Biologi, FKIP Universitas Mataram, Mataram
}

https://doi.org/10.29303/jpmpi.v3i2.1385

Sitasi: Nabella, R. P., Adiyatma, D., Muniro, N., Nabilah., Febrianti. B. T., Jagadraya, R \& Japa, L. (2022). Analisis Potensi Alam Desa Kwang Rundun Untuk Menunjang Konsep Ekowisata Serta Identifikasi Desa Kwang Rundun Sebagai Desa Wisata. Jurnal Pengabdian Magister Pendidikan IPA, 5(1)

\author{
Article history \\ Received: 11 Januari 2022 \\ Revised: 01 Februari 2022 \\ Accepted: 07 Februari 2022 \\ *Corresponding Author: \\ Lalu Japa, Prodi \\ Pendidikan Biologi, FKIP \\ Universitas Mataram, \\ Mataram, Indonesia; \\ Email: ljapa@unram.ac.id
}

\begin{abstract}
Abstrak: Sektor pariwisata yang ada di Nusa Tenggara Barat telah berkembang sangat pesat, dengan jumlah obyek tujuan wisata, pengunjung dan bentuk atraksi wisata yang terus mengalami peningkatan. Untuk memastikan perkembangan itu berdampak pada kesejahteraan masyarakat maka perluadanya peranan aktif semua pihak diantaranya pemerintah, praktisi, masyarakat dan akademisi khususnya dosen serta mahasiswa. Mahasiswa bisa ikut serta memajukan pariwisata melalui program kegiatan KKN. Kelompok KKN Terpadu Universitas Mataram tahun ini mencoba melakukan salah satu strategi dengan cara membuat papan penujuk arah dan promosi video wisata yang ada di Desa Kwang Rundun Kecamatan Jerowaru, Kabupaten Lombok Timur, NTB. Desa Kwang Rundun memiliki beberapa macam potensi yang bisa dikembangkan dan dimanfaatkan sebagai obyek kegiatan ekowisata. Potensi tersebut berupa bentangan alam dan budaya seperti PantaiGili Lunjer, zona jagung, kegiatan madanimba dan tradisi bau nyale. Tapi sayangnya potensi yang dimiliki selama ini justru tidak dioptimalisasikan secara tepat. Salah satunya adalah Pantai Gili Lunjer, yang masih memiliki pemandangan asri ini kurang dioptimalkan untuk kegiatan short trip maupun long trip. Oleh karena itu program kerja KKN yang dilaksanakan adalah Pengembangan Potensi Wisata di Desa Kwang Rundun melalui pembuatan papan penunjuk arah dan promosi wisata di social media agar potensi wisata di Desa Kwang Rundun lebih dikenal masyarakat luas.
\end{abstract}

Keywords: Potensiekowisata, ekowisata, desawisata

\section{Pendahuluan}

Belakangan ini kemajuan perekonomian dari sektor pariwisata yang ada di Nusa Tenggara Barat telah berkembang sangat pesat, dengan
Jumlah pengunjung yang terus meningkat setiap tahunnya. Berdasarkan Data Dinas Kebudayaan dan Pariwisata ProvinsiNusa Tenggara Barat 2019, bahwa jumlah kunjungan wisatawan yang datang ke Nusa Tenggara Barat (NTB) menembus angka 2.812.379 juta pengunjung pada tahun 2018, menurun dari tahun sebelumnya dengan pencapaian 
3.508.903 juta pengunjung pada tahun 2017 namun meningkat lagi pada tahun 2019 mencapai 3.706.352 juta wisatawan (Dinas Kebudayaan dan Pariwisata NTB, 2019).

Pencapaian jumlah pengunjung yang luar biasa ini tentu didukung oleh berbagai penghargaan yang telah didapatkan oleh Provinsi Nusa Tenggara Barat dalam bidang pariwisata seperti World's Best Halal Tourism Destination, World's Best Halal HoneymoonDestination, 4 penghargaan sekaligus dari Kompetisi Pariwisata Halal Nasional (KPHN) 2016 oleh menteri pariwisata dan ditambah lagi pada tanggal 7 Desember 2016 di Abu Dhabi, Nusa Tenggara Barat mendapatkan penghargaan World's Best Halal Beach Resort. Atas berbagai prestasi yang telah dicapai ini, maka membuka peluang besar untuk menjadikan Nusa Tenggara Barat sebagai poros destinasi pariwisata unggulan di Indonesia. Untuk menggapai itu semua maka pembenahan dari berbagai macam aspek tak bisa dielakkan. Peranan kita semua, pemerintah, akademisi dan seluruh masyarakat untuk saling mendukung dalam mewujudkan itu semua.Pergeseran konsep kepariwisataan saat inimenuju pariwisata minat khusus atau yang dikenal dengan ekowisata merupakan sebuah peluang besar bagi wilayah dengan potensi alam. Hal ini terjadi akibat kecenderungan semakin banyaknya wisatawan yang mengunjungi objek berbasis alam dan budaya penduduk lokal(Murianto\& Masyhudi, 2018).

Untuk mempercepat pertumbuhan pariwisata di wilayah Provinsi Nusa Tenggara Barat terutama di Pulau Lombok maka salah satu strategi yang dilakukan adalah dengan mengembangkan desa wisata yang ditetapkan sebagai program unggulan sesuai RPJMD-NTB tahun 2019-2023 guna mewujudkan NTB sejahtera dan mandiri. Meningkatnya wisatawan pun juga ditandai dengan tren-tren wisata yang berkembang seiring dengan motivasi wisatawan yang juga terusberkembang. Wisatamasal adalah salah satutren yang berkembang di masyarakat, di mana masyrakat melakukan kegiatan secara masal atau berkelompok. Sebuah tren baru berkembang di kalangan masyarakat setelah perkembangan wisatawan masal. Tren baru tersebut adalah perjalanan alami yang bertujuan untuk konservasi sumber daya alam atau yang biasa disebut ekowisata (Aja \& Arida, 2020). Trenekowisata ini mulai diminati masyarakat sejak perkembangan wisata masal yang sangat masif.

Desa Kwang Rundun yang terletak di Kecamatan Jerowaru, Kabupaten Lombok Timur, Provinsi NTB merupakan salah satu desa yang memiliki banyak potensi untuk dikembangkan menjadi obyek kegiatan pariwisata. Potensi wisata di desa ini terdiri dari potensi alam dan budaya. Kegiatan kebudayaan yang dipadukan dengan pariwisata disertai dengan konsep pengelolaan yang baik akan berpotensi memberi nilai tambah bagi sumber daya manusia dan meningkatkan kesejahteraan masyarakat (Purwana: 2018). Potensi alam meliputi sepertipantai dan struktur perbukitan. Sedangkan potensi budaya tradisional termasuk kegiatan sisir pantai dan festival budaya. Potensipotensi ini cocok untuk dikembangkan menjadi obyek ekowisata. Kehidupan masyarakat di desa yang masih relatif tradisional dan keunikan bentang alam daerah pesisir menjadi alternatif bagi wisatawan. Kemudahan akses ke Desa Kwang Rundun didukung dengan jalan beraspal dan tidak terlalu jauh dari ibu kota kabupaten. Potendipotensi yang ada di Desa Kwang Rundun berpeluang untuk dijadikan sebagai ekowisata. Ekowisata merupakan suatu bentuk pariwisata yang terutama terinspirasi oleh sejarah alam suatu daerah, termasuk budaya aslinya (Asy'ari et al., 2021).Istilah ekowisata dapat diartikan sebagai perjalanan oleh seorang turis ke daerah terpencil dengan tujuan menikmati dan mempelajari mengenai alam, sejarah dan budaya di suatu daerah, dimana pola wisatanya membantu ekonomi masyarakat lokal dan mendukung pelestarain alam (Murianto \& Masyhudi, 2018). Ciri-ciri ekowisata biasanya mengandung unsur utama, yaitu konservasi, edukasi untuk berperan serta, dan pemberdayaan masyarakat setempat. Konsep ekowisata menitikberatkan pada tigahal utama yaitu: 1) keberlangsungan alam atau ekologi; 2) memberi manfaat ekonomi; dan 3) secara psikologis dapat diterima dalam kehidupan sosial masyarakat. (Susanto et al., 2012). Lebih lanjut ciri-ciri ekowisata yang telah diungkapkan oleh Susanto sesuai dengan potensi yang dimiliki oleh Desa Kwang Rundun.Potensi-potensi ini dipandang perlu untuk ditata dan dikemas agar dapat dikembangkan sebgai daya tarik wisata. Apalagi tren wisata saat ini cenderung mengarah kepada ekowisata yang merupakan peluang yang harus 
dimanfaatkan dan dikembangkan secara maksimal potensi-potensi yang ada di Desa Kwang Rundun.

\section{Metode}

Kegiatan pengabdian ini dilakukan di Desa Kwang Rundun, Kecamatan Jerowaru, Kabupaten Lombok Timur, Provinsi Nusa Tenggara Barat. Pengabdian ini dilakukan untuk menemukan potensi alam yang terdapat di Desa Kwang Rundun yang dapat menunjang konsep ekowisata. Selain itu untuk melihat kesiapan Desa Kwang Rundun dalam menerapkan ekowisata. Ruang lingkup dalam kegiatan pendataan ini adalah potensi wisata yang berupa panorama alam dan budaya, kesiapan masyarakat Desa Kwang Rundun. Teknik pengumpulan data dan informasi dalam kegiatan pendataan ini yaitu wawancara, observasi langsung di lapangan dan studi kepustakaan. Tujuan dari kegiatan ini adalah mengetahui potensi alam yang menunjang konsep ekowisata yang ada di Desa Kwang Rundun.

Pelaksanaan operasional program-program KKN terpadu yang telah direncanakan akan dilaksanakan melalui partisipasi aktif mahasiswa di masyarakat Desa Kwang Rundun, Kecamatan Jerowaru. KKN terpadu Universitas Mataram 2021 di Desa Kwang Rundun melibatkan beberapa pihak diantaranya yaitu mahasiswa KKN, perangkat desa, kelompok sadar wisata dan masyarakat Desa Kwang Rundun. untuk menunjang kegiatan wisata di Desa Kwang Rundun diperlukan berbagai fasilitas pendukung yang memadai untuk kegiatan pariwisata, oleh karena itu program kerja KKN terpadu Desa Kwang Rundun disesuaikan dengan tujuan awal untuk memebantu meningkatkan dan mengembangkan potensi wisata di wilayah Desa Kwang Rundun agar lebih dikenal dan diketahui oleh masyarakat luas, dengan cara promosi pariwisata Pantai Gili Lunjer serta penambahan fasilitas pendukung lainnya seperti dalam bentuk papan penunjuk arah di Desa Kwang Rundun.

\section{Hasil dan Pembahasan}

\section{Potensi Alam di DesaKwangRundun Pantai Gili Lunjer}

Pantai Gili Lunjer adalah salah satu Pantai yang berada di wilayah administratif DesaKwangRundun. Pantai ini dulu dikenal dengan nama Pantai Kaliantan Selantan, yang kemudian berubah nama menjadi PantaiGili Lebur hingga akhirnya diganti Kembali menjadi Pantai Bowok Gili Lunjer yang dikenal sampai sekarang. Pemeberian nama PantaiBowok ini tidak lepas dari banyaknya ditemukan salah satu biota laut yaitu bulu babi yang dikenal sebagai bowok oleh masyarakat setempat. Kemudian asal nama Gili Lunjer sendiri dari kata gili yang berarti pulau kecil dan lunjer yang berarti berdiri tegak. Pulau kecil yang berdiri tegak sebagai ikon Pantai inilah yang menjadi asal usul nama Pantai Gili Lunjer (Gambar 1).

Pantai ini sendiri memiliki tekstur pasir pantai seperti merica dengan pasir yang berwarna putih (Gambar 2). Ekosistem di Pantai ini juga masih sangat terjaga dengan baik dan masih belum terjamahkanpantai ini oleh wisatawan. Hermitcrab atau yang dikenal masyarakat setempat sebagai keliomang masih bisa ditemukan disini berkeliaran dengan bebas di sekitaran pasir Pantai Gili Lunjer. Selain Hermitcrab spesies lain yang sering dijumpai disini adalah bulu babi atau bowok. Bowok sendiri sering dikonsumsi oleh masyarakat setempat.

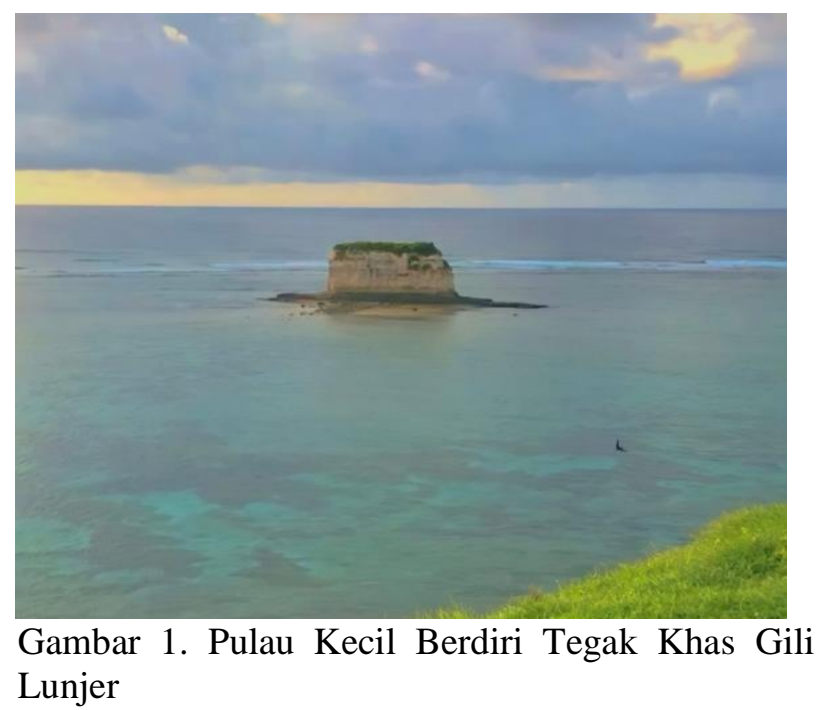




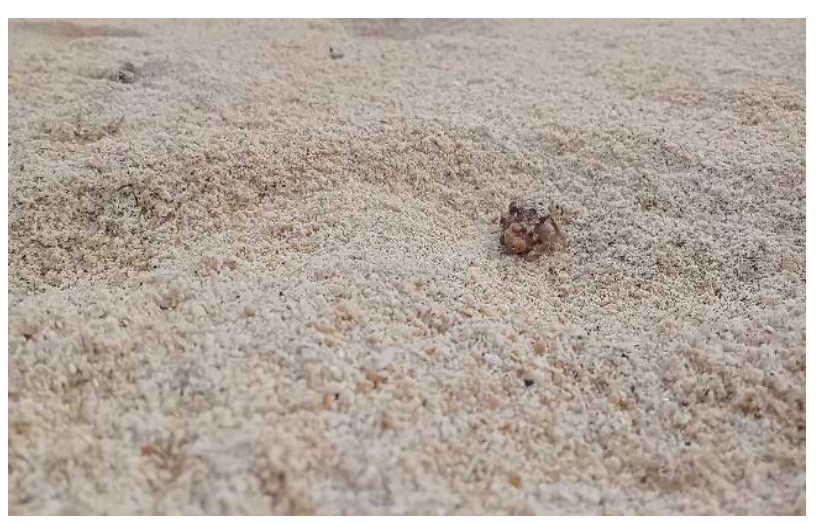

Gambar 2. Tekstur Pasir Gili Lunjer Serta Biota Laut yang Dapat Ditemukan

Terdapat kolam alami yang terbentuk dari bebatuan koral sepanjang garis PantaiGili Lunjer menjadi daya tarik tersendiri pantai ini. Kolam ini sendiri terbentuk akibat adanya cekungan Pantai Gili Lunjer yang terisi oleh air Pantai Gili Lunjer. Selain kolam alami struktur sekeliling PantaiGili Lunjer yang berupa perbukitan membuat pantai ini memiliki salah satu bukit khas di sebelah timur Pantai ini. Bukit dengan rumput khas bukit Merese ini menjadi daya saing dari pantai ini. Alaminya ekosistem Gili Lunjer serta pemandangan alami yang masih terjaga membuat banyak wisatawan yang melakukan kegiatan berkemah di pantai ini. Kegiatan menyaksikan purnama sambil berkemah juga sering di adakan di pantai ini, kegiatan ini biasanya di selenggarakan oleh pemerintah desa setempat bersama kelompok sadar wisata Desa Kwang Rundun. Aksesibilitas menuju Pantai Gili Lunjer ini ditunjang dengan jalan beraspal yang menghubungkan Desa Kwang Rundun dan Desa Ekas Buana, sedangkan untuk munju Pantai Gili Lunjer ini dari jalan utama masih berupa jalan tanah yang akan mengalami becek dan licin selama musim penghujan.

Kelompok sadar wisata Desa Kwang Rundun selaku otoritas tunggal yang memegang peranan penting dalam penyediaan fasilitas dan daya Tarik wisatawan untuk berkunjung ke pantai Gili Lunjerini. Pantai ini masih tergolong kurang diketahui oleh wisatawan lokal dan internasional ketimbang pantai yang berada sekitar Kawasan Kwang Rundun seperti pantai Kura-Kura dan Pantai Surga.

\section{Zona Jagung Kwang Rundun}

Pada periode bulan Desember hingga bulan April, Kawasan sepanjang perjalanan menuju
Desa Kwang Rundun dan Pantai Gili Lunjer terbentang hamparan bukit yang ditanami jagung (Gambar 3). Mayoritas penduduk Desa Kwang Rundun bekerja sebagai petani maka semua areal ladang yang dimiliki warga ditanami jenis tumbuhan yang sama.

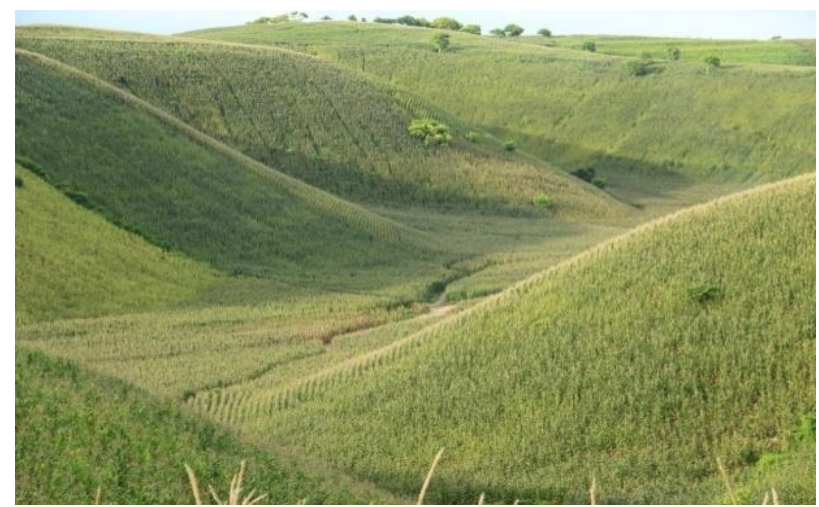

Gambar 3. Kawasan Bukit Jagung Sepanjang Perjalanan Ke Pantai Gili Lunjer

Pada musim penghujan areal ladang dan bukitberubah menjadi zona jagung yang membentang dari daerah Pemongkong sampai daerah Kaliantan. Struktur geografi wilayah Desa Kwang Rundun di daerah perbukitan menjadikan Kawasan jagung ini sebagai ciri khas tersendiri (Gambar 3).

Semua areal perbukitan sampai Kawasan PantaiGili Lunjer membentang bukit hijau yang di tutupi tanamanjagung. Hal ini membuat Kawasan tegalan dan bukit di wilayah Desa Kwang Rundun ini menarik banyak wisatawan untuk berhenti sejenak dan mengambil foto. Selain sebagai swafoto zona jagungDesaKwangRundun ini memiliki potensi besar sebagai daerah untuk mempelajari bagaimana kegiatan bercocok tanam. Jika pada bukan musim penghujan masyarakat setempat biasanya menanam jenis tanaman yang cocok di daerah kering dengan curah intensitas hujan yang rendah. Sehingga pada musim kemarau masyarakat Desa Kwang Rundun banyak menanam tembakau. Kawasan struktural perbukitan masih menjadi daya Tarik wisatawan dalam memilih destinasi wisata. Desa Kwang Rundun dapat memberikan atensi lebih ke areal perbukitan ini seperti yang dilakukan oleh Desa Ekas Buana dalam pemberian fasilitas zona jagung, seperti tempat swa foto dan rekreasi atau berekowisata. 


\section{Kegiatan Mada Nimba}

Kegiatan madanimba merupakan kegiatan sisir Pantai yang sering dilakukan oleh masyarakat setempat. Mada nimba sendiri dilaksanakan pada pagi atau sore hari saat air laut tengah surut. Desa Kwang Rundun yang terletak di pesisir Pantai membuat masyarakatnya akrab dengan hasil bahari. Pada saat air laut surut beberapa warga Desa Kwang Rundun akan turun ke pantai untuk melakukan sisir laut (madanimba). Sisir laut ini ditujukan untuk mencari biota laut yang dapat dikonsumsi sebagai lauk. Masyarakat sekitar akan berjalan dari pesisir pantai hingga tengah laut untuk mencari bulu babi/bowok (Gambar 4) yang menjadi ciri khas Pantai ini, kemudian kepiting, ikan kecil lainnya serta babycrab yang juga sering dijumpai di Pantai ini. Wisatawan akan ditemani warga desa setempat saat melakukan madanimba, hal ini dikarenakan bervariasinya biota laut yang akan dijumpai wisatawan baik yang beracun dan tidak. Sehingga pendampingan oleh masyarakat sekitar akan membantu wisatawan dalam memilih biota laut yang dapat dibawa pulang dan dikonsumsi ataupun biota yang sengaja ditangkap termasukikan hias.

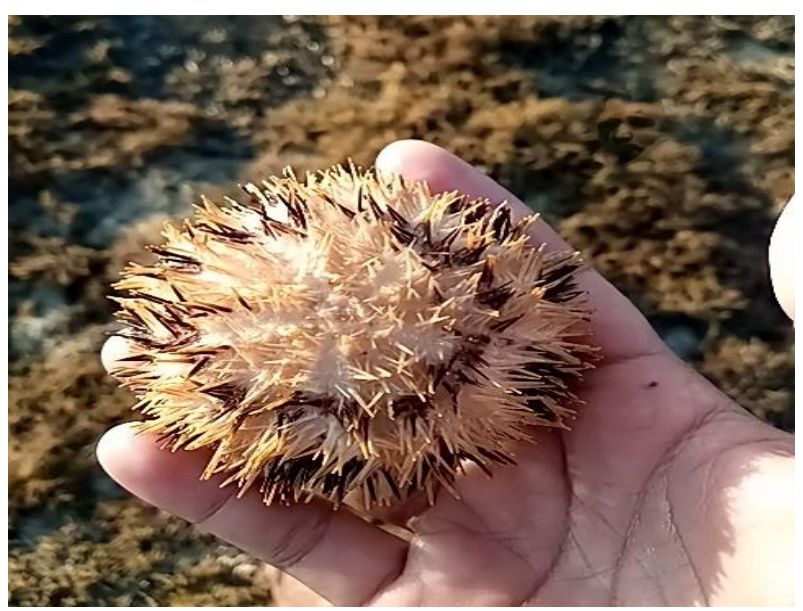

Gambar 4. Bowok Salah Satu Biota Laut yang dapat Dijumpai Saat Kegiatan Madanimba

\section{Festival Bau Nyale}

Festival bau nyale merupakan upacara tradisional yang dilakukan masyarakat Lombok terutama masyarakat Lombok Tengah dan Lombok Timur. Masyarakat pesisirselatanPulau Lombok sudah ratusan tahun melakukan tradisi bau nyale (Bachtiar et al., 2020b). Dalam kepercayaan adat sasak nyalemerupakan jelmaan putri mandalika. Acara bau nyale tidak hanya diselenggarakan secara meriah oleh masyarakat Lombok tengah di Pantai Seger dan Kuta, tetapitermasukmasyarakat Lombok Timur di kawasan Pantai Kaliantan dan Pantai Kura-kura. Pada periode bau nyale masyarakat selatan akan ramai berbondong bonding tumpah ruah turun ke laut untuk menangkap nyale (bau nyale istilah dalam bahasa Suku Sasak). Acara bau nyale rutin dilakukan setiap tahun pada hari ke 20 bulan ke 10 dalam kalender suku sasak. Nyale yang tidak lepas dari cerita rakyat masyarakat sasak terbilang cukup unik, nyale hanya muncul setahun sekali dan dikawasan tertentu pesisirselatan Pulau Lombok seperti Pantai Kuta, Pantai Seger, Kecamatan Pujut Lombok Tengah dan Kawasan pantai selatan lainnya termasuk dari Pantai Kurakura, Gili Lunjer serta dan Pantai Kaliantan, Kecamatan Jerowaru Lombok Timur. Tradisi bau nyale di wilayah Kecamatan Jerowaru juga dilaksanakan setiap tahun dan merupakan kebanggaan masyarakat Kabupaten Lombok Timur (Bachtiar, et al., 2020a). Lebih lanjut Bachtiar, et al. (2019, 2020a) menegaskan, bahwa tradisi bau nyale telah dikemas dalam atraksi wisata budaya yang berdampak pada penangkap nyale tidak terbatas pada masyarakat tradisionalPulau Lombok tetapi juga oleh wisatawan asing maupun lokal.

Masyarakat selatan meyakini, nyalenyale yang keluar berhubungan dengan kesejahteraan dan keselamatan. Mereka percaya bahwa jika banyak nyale yang keluar dari laut maka hasil pertanian juga akan melimpah. Masyarakat DesaKwangRundun saat festival bau nyale akan tumpah ruah di PantaiGili Lunjer hingga Kaliantan untuk menangkap nyale, nyale tersebut akan dibawa pulang untukdijual atau dikonsumsi.

\section{Identifikasi Potensi Desa Wisata}

Desa wisata merupakan integrasi antara atraksi, akomodasi dan fasilitas-fasilitas pendukung yang ada pada struktur kehidupan masyarakat yang menyatu pada budaya dan tradisi yang khas di daerah tertentu. Desa wisata memiliki daya tarik tersendiri agar diminati oleh wisatawan. Potensi Desa Kwang Rundun sebagai desa wisata dengan menunjang konsep ekowisata diidentifikasi dengan mengevaluasi syarat-syarat desa wisata sebagai berikut 1) Kenunikan dan keaslian, 2) Letak dan aksesibilitas, 3) Budaya yang mencakup adat istiadat 4) Sarana dan prasarana pendukung, 5) Alam, 6) Partisipasi masyarakat lokal 7) terjaminnya keamanan, ketertiban dan kebersihan (Permadi et al., 2018). Berdasarkan syarat-syarat 
tersebut berikut hasil identifikasi Desa Kwang Rundun sebagai desa wisata.

\section{Keunikan dan Keaslian, dari SegiAlam, Sosial Budaya dan Industri.}

Potensi alam di Desa Kwang Rundun secara umum masih asri, contohnya adalah Pantai Gili Lunjer secara umum Pantai ini memlikikawasan yang asri dengan atraksi mandi di Pantai,berkemah serta kegiatan lainnnya yang bisa dilakukan adalah memancing kegiatan social budaya sebgai penunjang konsep ekowisata di KwangRundun yaitu kegiatan madanimba dan bau nyale yang dilakukan di PantaiKura-kura dan gili lunjer.

\section{Letak dan Aksesibilitas}

Letak kecamatan Jerowaru yang cukup jauh dari ibu kota provinsi NTB Mataram sekitar 70 Kilometer. Sedangkan jarak Desa Kwang Rundun dari ibu kota provinsi sekitar 75 kilometer. Namun dari arah BandaraInternasionalLombok ke desa ini dapat ditempuh dalam waktu satujam perjalanan. Untuk akses jalan menuju obyek wisata di Desa Kwang Rundun khsususnya obyek wisata Pantai Gili Lunjer sudah beraspal namun untuk mencapai akses ke Pantai Gili Lunjer dari jalan utama masih jalan tanah.

\section{Obyek Wisata dan Atraksi Pariwisata Utama}

Dari hasil wawancara dengan pemerintah setempat, obyek wisata dikawasan Desa Kwang Rundun diantaranya Pantai Gili Lunjer dan zona perbukitan sepanjang jalan menuju Pantai gili lunjer. Atraksi pariwisata yang ditawarkan adalah kegiatan madanimba dan festival bau nyale. Kearifan lokal masyarakat Kwang Rundun yang potensial juga dapat menunjang konsep ekowisata, seperti kegiatan bertani, berternak serta kentalnya adat sasak yang ditunjukkan oleh semua staf pemerintah Desa Kwang Rundun pada setiap hari kamis mengenakan pakaian adat songket khas sasak

\section{Sarana dan Prasarana Pendukung}

Dari identifikasi terhadap sarana dan prasarana desa potensial menjadi desa wisata berbasis ekowisata, diketahui fasilitas sekitar DesaKwangRundun terdapat hotel dan penginapan yang memadai seperti Heavenonthe planet resort, Villa surf dan Ekas Sunrise. Yang menjadi permaslahan desa-desa di wilayah Kecamatan Jerowaru adalah terbatasnya akomodasi (Permadi et al., 2018). Sedangkan di tempat wisatanya sendiri yakni di Pantai Gili Lunjer fasilitas penunjang seperti tempat sanitasi, tempat beribadah belum tersedia. Sedangkan gazebo di Pantai Gili Lunjer hanya terdapat satu gazebo. Sehingga untuk sarana dan pransarana pendukung di Kawasan wisata itu sendiri masih kurang memadai.

\section{Partisipasi Masyarakat Lokal}

Banyaknya potensi alam dan manusiasangat mendukung gerakan pariwata dengan pemanfaatan potensi dari hasil industri kecil, pertaniandan perkebunan untukdiintegrasikan dengan wisata desa tematik yang tetap memperhatikan norma dan kearifan lokal. Kegiatan wisata berbasis kearifan lokal melibatkan partisipasi masyrakat secara aktif (Nuurlaily et al., 2020). Partisipasi masyarakat Desa Kwang Rundun saat ini dalam pariwisata terbilang sudah mulai menggeliat, dengan adanya komunitas kelompok sadar wisata Desa Kwang Rundun yang disahlan tahun 2018. Menunjukkan keseriusan pemerintah Desa Kwang Rundun dalam mengembangkan potensi wisata Desa Kwang Rundun. kegiatan promosi untuk wisata daerah Kwang Rundun juga gencar dilakukan salah satunya adalah dengan promosi di sosial media, salah satunya adalah akun @ Pantai_gililunjer yang merupakan akun Instagram untuk mempromosikan Pantai Gili Lunjer yang di Kelola oleh Pokdarwis setempat.

Berdasarkan penelitian yang dilakukan oleh Permadi et al. 2018, Desa Kwang Rundun memenuhi lima dari tujuh syarat dalam menunjang keberhasilan sebagai desawisata. Namun demikian potensi alam Desa Kwang Rundun disebut cukup potensial untuk dijadikan konsep ekowisata.

\section{Kesimpulan}

Potensi ekowisata yang terdapat di Desa Kwang Rundun terdiri dari potensi alam dan budaya yaitu Pantai Gili Lunjer, areal perbukitan zona jagung, kegiatan madanimba dan acara bau nyale. Potensi-potensi ini dapat dikembangkan menjadi kegiatan ekowisata seperti berkemah di Pantai Gili Lunjer serta mengamati kegiatan masyarakatlokal atau berpatisipasi dalam kegiatan madanimba maupun bau nyale. Berdasarkan analisis tingkat kesiapannya desaKwangRundun masih termasuk dalam kategori rintisan desa wisata. Namun demikian tidak menutup kemungkinan jika diberikan atensi lebih jauh Desa Kwang Rundun berpotensi menjadi desa wisata permulaan maupun desa wisata paripurna. 


\section{Ucapan Terimakasih}

Kegiatan KKN mahasiswa di Desa Kwang Rundun KecamatanJerowaru, Lombok Timur dapat dilaksanakan dengan lancar sampai dihasilkannya artikel ini adalah karena dukungan dari berbagai pihak termasuk LPPM Universitas Mataram, Kepala Desa Kwang Rundun beserta staf administrasinya, kelompok sadar wisata dan masyarakat Desa Kwang Rundun. Untuk itu, disampaikan terimakasih sebesar-besarnya. Terimakasih juga atas dukungan moril dan material serta patisipasi aktif masyarakat Desa Kwang Rundun dalam proses kegiatan KKN Terpadu Universistas Mataram periode November 2021Januari 2022.

\section{Daftar Pustaka}

Aja, A. F., \& Arida, I. N. S. (2020). Analisis Potensi Ekowisata dan Kesiapan Masyarakat Desa Rendu Tutubadha dalam Pengembangan Ekowisata. Jurnal Destinasi Pariwisata, $8(2): 225$.

Asy'ari, R., Dienaputra, R. D., Nugraha, A., Tahir, R., Rakhman, C. U., \& Putra, R. R. (2021). Kajian Konsep Ekowisata Berbasis Masyarakat Dalam Menunjang Pengembangan Pariwisata: Sebuah Studi Literatur. Pariwisata Budaya: Jurnal Ilmiah Pariwisata Agama Dan Budaya, 6(1): 9-19.

Bachtiar, I., Japa, L., dan Bahri, S. (2020a). Peningkatan Pengetahuan Guru Biologi SMA Negeri Tentang Biologi Cacing Nyale Di Kabupaten Lombok Timur. Jurnal Pendidikan dan Pengabdian Masyarakat. 3(4):311-316.

Bachtiar, I., Japa, L., Bahri, S., dan Handayani, B.S. (2020b). Modul Pembelajaran Biologi Cacing Nyale. Mataram University Press. Matara

Bachtiar, I., Japa, L., Santoso, D. dan Syachruddin, AR. (2019). Peningkatan Pengetahuan Guru IPA SMP/MTs Tentang Biologi Cacing Nyale Di Kecamatan Pujut Kabupaten Lombok Tengah. Jurnal Pendidikan dan Pengabdian Masyarakat. 2(4):433-437.

Purwana, B.H.S. (2018). Potensi Ekowisata Berbasis Budaya Masyarakat ( Social Cultural Based Tourism Potency in Senaru Village , North Lombok Regency ). Jurnal Kebudayaan, 13(2):91-106.
Murianto, \& Masyhudi, L. (2018). Strategi Pengembangan Ekowisata Berbasis Masyarakat Lokal Di Teluk Seriwe Lombok Timur. Media Bina Ilmiah, 13(2):913-924.

Nuurlaily, S., Anak Agung Sagung Alit Widyastuty, \& Annisa Budhiyani Tribhuwaneswari. (2020). Penguatan Promosi Desa Wisata Berbasis Kearifan Di Desa Pujon Kabupaten Malang. Jurnal Penamas Adi Buana, 4(1):5-12.

ntbprov.go.id. (2019, 25 Juli). Desa Wisata Kembang Kuning, Simpan Sejuta Pesona. Diakses pada 08 Januari 2022, dari https://www.ntbprov.go.id/post/programunggulan/desa-wisata-kembang-kuningsimpan-sejuta-pesona

Permadi, L. A., Asmony, T., Widiana, H., \& Hilmiati, H. (2018). Identifikasi Potensi Desa Wisata di Kecamatan Jerowaru, Lombok Timur. Jurnal Pariwisata Terapan, 2(1):33.

Susanto, E., Zuhri, M. T., \& Muwuri, K. (2012). Konsep Pengembangan Desa Ekowisata Pampang Berbasis Partisipasi Masyarakat. Kritis, 28(2): 149-161. 